\title{
Do Commonly Used Ventilator Settings for Mechanically Ventilated Adults Have the Potential to Embed Secretions or Promote Clearance?
}

\author{
George Ntoumenopoulos PhD Grad Dip Clin Epid, Harriet Shannon PhD, and \\ Eleanor Main MSc PhD
}

\begin{abstract}
BACKGROUND: Intubation and mechanical ventilation can impair mucociliary clearance and cause secretion retention, airway occlusion, atelectasis, and pneumonia. Animal and laboratory work has demonstrated that mechanical ventilator settings can generate a flow bias (inspiratory or expiratory) that may result in mucus movement either away from the ventilator (deeper into the lungs) or toward the ventilator (toward the mouth), respectively. An absolute difference of $17 \mathrm{~L} /$ min, and a relative difference of $\geq 10 \%$, between the expiratory and inspiratory flow have been reported as thresholds for mucus movement. METHODS: We measured baseline peak inspiratory and expiratory flows during quiet mechanical ventilation in a convenience sample of 20 intubated and ventilated adult patients. RESULTS: Nineteen patients had an inspiratory flow bias of $\geq 10 \%$. Eight patients had an absolute mean inspiratory flow bias of $\geq 17 \mathrm{~L} / \mathrm{min}$. CONCLUSIONS: Commonly used mechanical ventilator settings generate an inspiratory flow bias that may promote secretion retention. Key words: mechanical ventilation; mucus; secretion clearance. [Respir Care 2011; 56(12):1887-1892. (C) 2011 Daedalus Enterprises]
\end{abstract}

\section{Introduction}

Endotracheal tube (ETT) intubation and mechanical ventilation are an essential component of intensive care for critically ill patients, but can impair mucociliary clearance and cause secretion retention, airway occlusion, atelectasis, and pneumonia. ${ }^{1}$ Well described risk factors include mucus hypersecretion caused by the underlying pathophysiology or by micro-trauma from the ETT, poor circuit

\footnotetext{
Dr Ntoumenopoulos is affiliated with the Physiotherapy Department, Guy's and St Thomas' National Health Service Foundation Trust, London, United Kingdom. Drs Shannon and Main are affiliated with the Portex Unit of Paediatric Anaesthesia, Pain Research, Critical Care, Respiratory Medicine, Physiology, and Physiotherapy, University College London Institute of Child Health, London, United Kingdom.
}

The authors have disclosed no conflicts of interest.

Correspondence: George Ntoumenopoulos PhD Grad Dip Clin Epid, Physiotherapy Department, Guy's and St Thomas' National Health Service Foundation Trust, Westminster Bridge Road, London, SE1 7EH United Kingdom. E-mail: georgentou@yahoo.com.

DOI: $10.4187 /$ respcare.01229 humidification, loss of mucociliary transport from the tip of the ETT, and compromised cough because of sedation and glottic splinting. ${ }^{1,2-6}$

SeE the Related Editorial on Page 1970

Inspiratory and expiratory air flow dynamics generated by ventilator settings may also contribute substantially to mucus movement, but this is less well recognized in the clinical environment and deserves some attention. Studies in animal and lung models have consistently demonstrated that inspiratory or expiratory flow bias can result in net migration of mucus in the direction of the flow bias. ${ }^{7-9}$ To move mucus cephalad so that it may be easily removed by suctioning or cough, an overall expiratory flow bias must exist. By contrast, net caudad mucus migration over many consecutive hours of mechanical ventilation may result in important clinical consequences for vulnerable patients.

Volpe et al, in a series of laboratory studies, confirmed that ventilator settings that produced flow bias had a major effect on mucus movement, with the potential either to clear or embed secretions. ${ }^{10}$ The results of laboratory stud- 


\section{Do Commonly Used Ventilator Settings Hinder Secretion Clearance?}

ies should be extrapolated with caution to the clinical environment, but the consistency of the findings of previous studies, and the fact that all the bench experiments used clinically plausible ventilator settings, suggest a credible and growing body of evidence that ventilator settings can promote or hinder secretion clearance.

The reported critical threshold of flow bias for mucus movement has differed slightly in the available studies, but there is general agreement that there must be a difference of at least $10 \%$ between the peak inspiratory and peak expiratory flows for net mucus migration to occur via 2-phase gas/liquid interaction. ${ }^{8,11}$ Volpe et al found that, with a $1.5 \%$ polyethylene oxide mucus stimulant, an absolute expiratory to inspiratory flow difference of $17 \mathrm{~L} / \mathrm{min}$ better explained the displacement of mucus than did the inspiratory to expiratory flow ratio. ${ }^{10}$

The aims of this observational study were to determine the inspiratory to expiratory flow bias during conventional ventilator settings in intubated adult patients, and to interpret those findings in the context of critical flow bias thresholds reported in the literature.

\section{Methods}

This study was approved by the ethics committee of Guy's and St Thomas' National Health Service Foundation Trust, London, United Kingdom, and conducted in its intensive care unit. As part of a larger clinical feasibility trial in mechanically ventilated adults who were deemed to require chest physiotherapy in the intensive care unit, we continuously recorded respiratory data during baseline mechanical ventilator settings. Consecutive eligible patients were recruited, and ventilator settings were not altered prior to data collection. Steady-state data were electronically recorded and downloaded for at least $15 \mathrm{~min}$ prior to any intervention, to prevent bias or influence from physiotherapy, nursing, or medical staff.

The baseline respiratory data we recorded included:

- Peak inspiratory and expiratory flow (PIF and PEF)

- Inspired and expired tidal volumes $\left(\dot{\mathrm{V}}_{\mathrm{I}}\right.$ and $\left.\dot{\mathrm{V}}_{\mathrm{E}}\right)$

- Inspiratory and expiratory time $\left(\mathrm{T}_{\mathrm{I}}\right.$ and $\left.\mathrm{T}_{\mathrm{E}}\right)$

- Peak inspiratory pressure (PIP)

- Positive end expiratory pressure (PEEP)

\section{Inclusion Criteria}

We screened patients who were admitted to the intensive care unit from June to September 2008, and included intubated and mechanically ventilated adult patients who required chest physiotherapy and were cardiovascularly stable. The inclusion criteria were deliberately broad in order to include a heterogeneous patient population.

\section{Exclusion Criteria}

We excluded patients at risk of pulmonary hemorrhage, with osteoporosis, or whose medical instability precluded physiotherapy, and patients who had an ETT leak of $>20 \%$.

\section{Equipment}

We measured respiratory variables with a noninvasive respiratory monitor $\left(\mathrm{CO}_{2} \mathrm{SMO}\right.$ Plus, Respironics, Wallingford, Connecticut). The disposable flow sensor was inserted between the closed-suctioning-catheter mount and the ETT, and measured air flow and pressure at a sampling frequency of $100 \mathrm{~Hz}$.

Before the study, to assess the accuracy of the individual flow and pressure sensors, we used a $500-\mathrm{mL}$ calibrated syringe (Hans Rudolph, Shawnee, Kansas) to inject volumes of $100 \mathrm{~mL}$ and $500 \mathrm{~mL}$ through the respiratory monitor, at various rates, and compared the known volume to the volume measured by the respiratory monitor. We deemed agreement within 5\% acceptable for this study.

\section{Protocol}

Each patient was positioned supine, and the head of the bed was elevated to $30-45^{\circ}$, in the absence of any other patient-care interventions. We assessed ETT leak and excluded the data if ETT leak was above 20\% despite repositioning the patient. ${ }^{12}$ No substantial leaks were expected, because we used cuffed ETTs. We continuously recorded stable baseline mechanical ventilation without any interventions (eg, airway suctioning or patient repositioning) for at least $15 \mathrm{~min}$.

We recorded details of the ventilation modes and settings from the patients' charts and directly from the ventilators. The mechanical ventilators used were the Evita XL (Dräger Medical, Lübeck, Germany) and the Avea (CareFusion, Hochberg, Germany). Ventilation modes mainly included spontaneous breathing on CPAP and pressure support (patient-triggered, flow-cycled breaths). Other modes included: Bi-level positive airway pressure (with a set breath rate, to transition from a high pressure to a low pressure, and which allows the patient to spontaneously breathe at both pressure levels); and pressure-regulated volume control (pressure-limited, time-cycled breaths with a set tidal volume and variable flow delivery, with pressure adjusted based on lung/ thorax compliance/resistance and patient effort).

\section{Data Analysis}

We analyzed 50 breaths per patient, which was the lowest common number of breaths in the 15-min recorded 


\section{Do Commonly Used Ventilator Settings Hinder Secretion Clearance?}

Table 1. Admission Diagnoses and Ventilation Modes

\begin{tabular}{|c|c|c|c|c|}
\hline $\begin{array}{l}\text { Patient } \\
\text { Number }\end{array}$ & Sex & $\begin{array}{l}\text { Age } \\
(y)\end{array}$ & Diagnosis & $\begin{array}{l}\text { Ventilation } \\
\text { Mode }\end{array}$ \\
\hline 1 & M & 58 & $\begin{array}{l}\text { Cardiac arrest ( } 5 / 7 \text { post- } \\
\quad \text { event) }\end{array}$ & CPAP/PS \\
\hline 2 & M & 80 & After abdominal surgery & CPAP/PS \\
\hline 3 & $\mathrm{~F}$ & 61 & Sepsis & BPAP \\
\hline 4 & $\mathrm{~F}$ & 26 & ARDS & CPAP/PS \\
\hline 5 & M & 78 & $\begin{array}{l}\text { After surgery for Fournier } \\
\text { gangrene }\end{array}$ & CPAP \\
\hline 6 & M & 53 & $\begin{array}{l}\text { Multiple myocardial } \\
\text { infarctions }\end{array}$ & CPAP \\
\hline 7 & $\mathrm{~F}$ & 40 & Decompensated liver failure & CPAP/PS \\
\hline 8 & M & 79 & Cerebrovascular accident & CPAP/PS \\
\hline 9 & M & 71 & Cardiogenic shock & CPAP/PS \\
\hline 10 & $\mathrm{~F}$ & 72 & Cerebrovascular accident & BPAP \\
\hline 11 & M & 18 & Hypoxic brain injury & CPAP/PS \\
\hline 12 & $\mathrm{~F}$ & 21 & Sepsis and pneumonia & CPAP/PS \\
\hline 13 & $\mathrm{~F}$ & 49 & $\begin{array}{l}\text { Community-acquired } \\
\text { pneumonia }\end{array}$ & CPAP \\
\hline 14 & M & 76 & After cardiac surgery & CPAP/PS \\
\hline 15 & M & 65 & COPD exacerbation & CPAP \\
\hline 16 & M & 70 & Respiratory distress & CPAP \\
\hline 17 & M & 71 & After cardiac arrest & CPAP \\
\hline 18 & $\mathrm{~F}$ & 48 & Tracheal stenosis/hypoxia & PRVC \\
\hline 19 & M & 62 & Acute renal failure & CPAP/PS \\
\hline 20 & M & 65 & COPD exacerbation & CPAP/PS \\
\hline $\begin{array}{l}\mathrm{CPAP}=\mathrm{co} \\
\mathrm{PS}=\text { press } \\
\mathrm{BPAP}=\mathrm{bi} \\
\mathrm{ARDS}=\mathrm{ac} \\
\mathrm{COPD}=\mathrm{cl} \\
\mathrm{PRVC}=\mathrm{pr}\end{array}$ & $\begin{array}{l}\text { inuous } \\
\text { suppor } \\
\text { vel posi } \\
\text { e respir } \\
\text { nic obs } \\
\text { sure-reg }\end{array}$ & $\begin{array}{l}\text { tive airy } \\
\text { airway } \\
\text { y distre } \\
\text { tive pul } \\
\text { ed volu }\end{array}$ & $\begin{array}{l}\text { pressure } \\
\text { essure } \\
\text { yndrome } \\
\text { nary disease } \\
\text {-control ventilation }\end{array}$ & \\
\hline
\end{tabular}

interval. We calculated leak during baseline data collection, with the following formula:

$$
\operatorname{Leak}(\%)=\left[\left(\dot{\mathrm{V}}_{\mathrm{I}}-\dot{\mathrm{V}}_{\mathrm{E}}\right) / \dot{\mathrm{V}}_{\mathrm{I}}\right] \times 100
$$

We calculated PEF/PIF and mean inspiratory-expiratory flow difference from the PIF and PEF raw data. We analyzed the respiratory monitor data (PIF, PEF, PIP, PEEP, $\mathrm{T}_{\mathrm{I}}, \mathrm{T}_{\mathrm{E}}, \dot{\mathrm{V}}_{\mathrm{I}}$, and $\dot{\mathrm{V}}_{\mathrm{E}}$ ) in statistics software (SPSS 18, SPSS, Chicago, Illinois), and compared the data to the bias-flow thresholds reported in previous studies $(10 \%$ and $17 \mathrm{~L} /$ $\min )$.

\section{Results}

We included 20 patients (13 males), whose mean \pm SD age was $60 \pm 17$ years. No patients were excluded due to ETT leak. Table 1 shows the admission diagnoses and ventilation modes. Seventeen patients were on spontaneous ventilation modes, and the rest were on bi-level positive airway pressure or pressure-regulated volume-con-
Table 2. Respiratory Variables During Stable Mechanical Ventilation*

\begin{tabular}{lc}
\hline \hline PIF $(\mathrm{L} / \mathrm{min})$ & $56 \pm 3$ \\
$\mathrm{PEF}(\mathrm{L} / \mathrm{min})$ & $37 \pm 2$ \\
$\mathrm{PIF} / \mathrm{PEF}(\%)$ & $1.6 \pm 0.4$ \\
$\dot{\mathrm{V}}_{\mathrm{I}}(\mathrm{mL})$ & $548 \pm 35.3$ \\
$\dot{\mathrm{V}}_{\mathrm{E}}(\mathrm{mL})$ & $512 \pm 233$ \\
$\mathrm{~T}_{\mathrm{I}}(\mathrm{s})$ & $0.85 \pm 0.22$ \\
$\mathrm{~T}_{\mathrm{E}}(\mathrm{s})$ & $2.18 \pm 1.10$ \\
$\mathrm{~T}_{\mathrm{I}} / \mathrm{T}_{\mathrm{E}}$ & $0.45 \pm 0.19$ \\
$\mathrm{PIP}\left(\mathrm{cm} \mathrm{H} \mathrm{H}_{2} \mathrm{O}\right)$ & $15.6 \pm 0.61$ \\
PEEP $\left(\mathrm{cm} \mathrm{H}_{2} \mathrm{O}\right)$ & $7.6 \pm 0.26$
\end{tabular}

\footnotetext{
* Values are mean \pm SD.

$\mathrm{PIF}=$ peak inspiratory flow

$\mathrm{PEF}=$ peak expiratory flow

$\dot{\mathrm{V}}_{\mathrm{I}}=$ inspiratory tidal volume

$\dot{\mathrm{V}}_{\mathrm{E}}=$ expiratory tidal volume

$\mathrm{T}_{\mathrm{I}}=$ inspiratory time

$\mathrm{T}_{\mathrm{E}}=$ expiratory time

PIP $=$ peak inspiratory pressure

PEEP $=$ positive end expiratory pressure
}

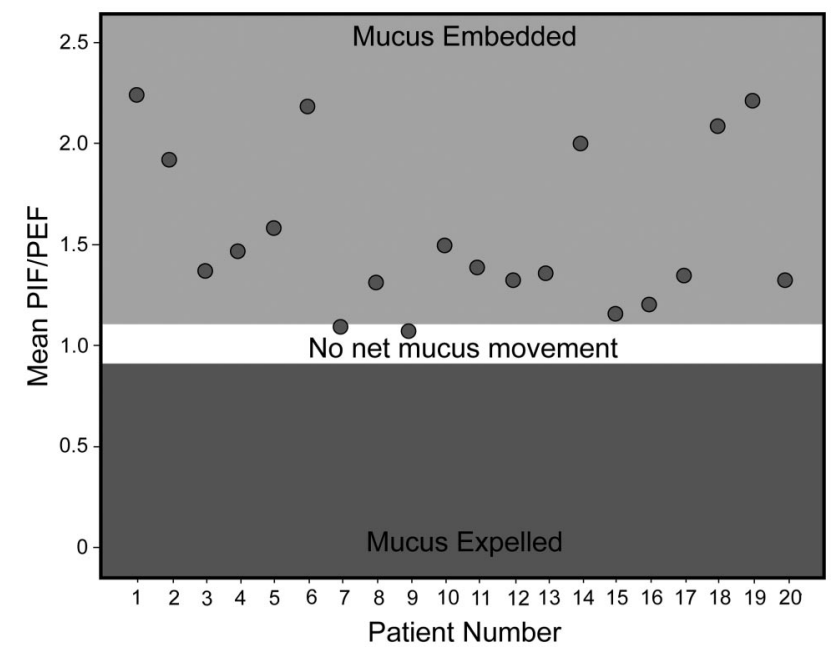

Fig. 1. Mean ratio of peak inspiratory flow (PIF) to peak expiratory flow (PEF) for all 20 patients. The shaded areas that start at 1.1 and 0.9 represent the inspiratory bias and expiratory bias, respectively, identified as mucus-movement thresholds by Kim et al, 8 and the white area between the shaded areas represents the range in which, theoretically, the flow bias would not move mucus caudad or cephalad.

trolled ventilation. The $\mathrm{F}_{\mathrm{IO}_{2}}$ range was $0.3-0.6$ (median 0.3). The intensive-care-unit stay range was 2-42 days (median $11 \mathrm{~d}$ ) prior to the study measurements. Table 2 shows the respiratory measurements.

Figure 1 shows the flow bias data. The mean \pm SD PIF/PEF was $1.6 \pm 0.4$. All the patients had an absolute inspiratory flow bias of $>0.9$, and all but one patient had an inspiratory flow bias of $>1.1$, which, theoretically, is sufficient to cause caudad mucus movement and thus embed secretions. Eight patients had an inspiratory flow bias 


\section{Do Commonly Used Ventilator Settings Hinder Secretion Clearance?}

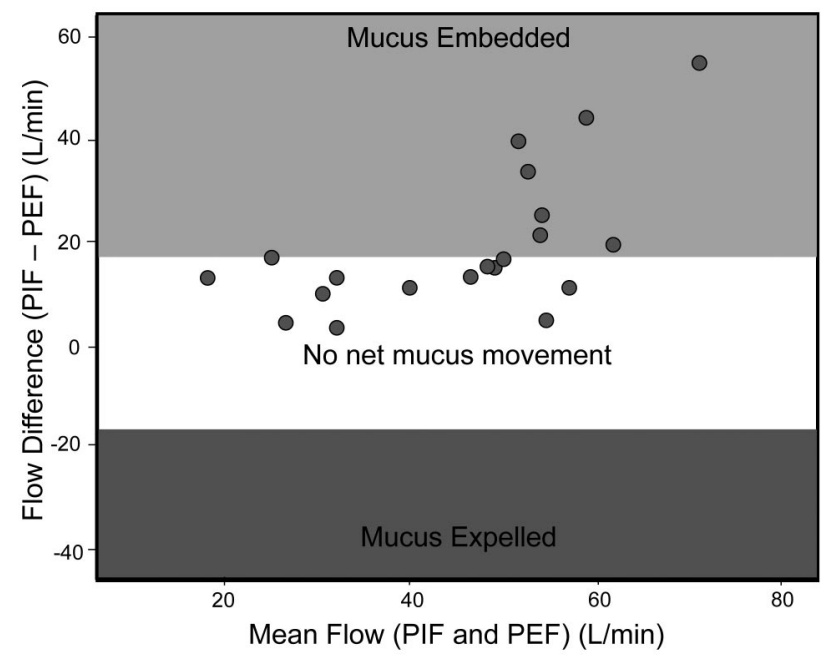

Fig. 2. Bland Altman plot of mean flow versus absolute difference between peak inspiratory flow (PIF) and peak expiratory flow (PEF). The shaded areas that start at 17 and -17 indicate the flow differences at which, theoretically, mucus would move caudad or cephalad.

of $\geq 17 \mathrm{~L} / \mathrm{min}$, the threshold that Volpe et al suggested would cause caudad mucus movement (Fig. 2). The other 12 patients had flow bias values that, theoretically, should result in no net mucus movement. None of the patients had flow-bias conditions that would have enhanced mucus clearance.

The highest mean inspiratory flow bias difference was $55.9 \mathrm{~L} / \mathrm{min}(95 \% \mathrm{CI}$ for inspiratory-expiratory flow difference $57.4-75.4 \mathrm{~L} / \mathrm{min}$ ) in patient 1 , who was on CPAP $\left(5 \mathrm{~cm} \mathrm{H}_{2} \mathrm{O}\right)$ and pressure support $\left(8 \mathrm{~cm} \mathrm{H}_{2} \mathrm{O}\right)$. He was a 58-year-old man admitted following cardiac arrest, and presenting with bilateral lower-zone infiltrates on chest radiograph (Fig. 3).

In contrast, the lowest mean inspiratory flow bias was only $3.2 \mathrm{~L} / \mathrm{min}(95 \% \mathrm{CI}$ for inspiratory-expiratory flow difference $3.8-11.9 \mathrm{~L} / \mathrm{min}$ ) in patient 15 , who was on CPAP $\left(7 \mathrm{~cm} \mathrm{H}_{2} \mathrm{O}\right)$ and pressure support $\left(16 \mathrm{~cm} \mathrm{H}_{2} \mathrm{O}\right)$. $\mathrm{He}$ was a 65 -year-old man admitted with cardiogenic shock (see Fig. 3).

The predominant use of CPAP and pressure support precluded analysis of the effect of ventilation mode on flow rate, because there were insufficient numbers of patients on the other modes (bi-level positive airway pressure and pressure-regulated volume-controlled ventilation).

\section{Discussion}

This preliminary investigation found that commonly used ventilator settings predominantly generated an inspiratory flow bias that may cause caudad mucus movement and secretion retention. Nineteen patients had an inspiratory flow bias of $\geq 10 \%$ during standard mechanical ventila-
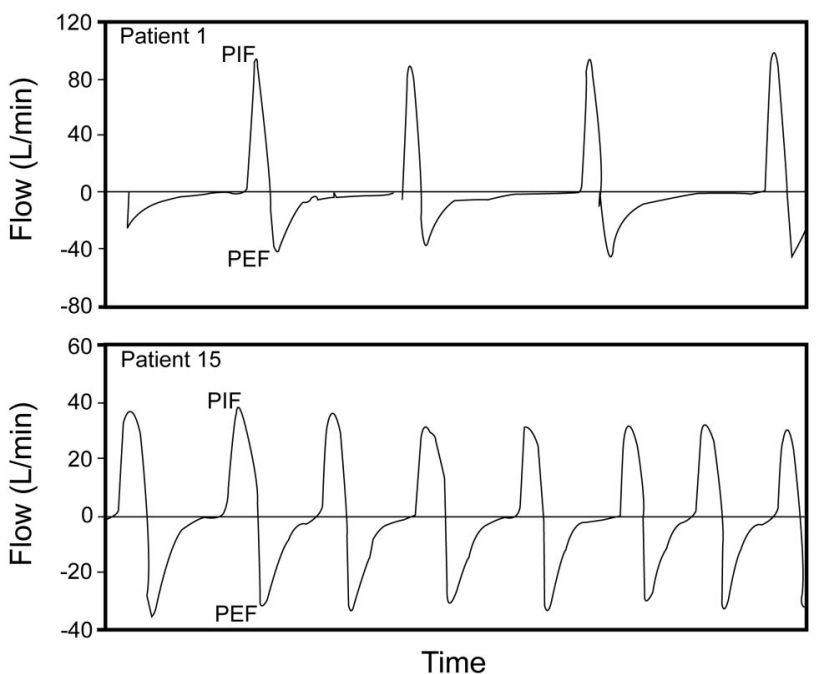

Fig. 3. Flow traces recorded during quiet ventilation in patients 1 and 15. Patient 1 has a substantial inspiratory flow bias because of a high peak inspiratory flow (PIF) and a low peak expiratory flow (PEF). In contrast, patient 15 has a lower ratio of PIF to PEF (close to 1), which theoretically should cause no net mucus movement in either direction.

tion. Eight patients also had an absolute difference of $\geq 17 \mathrm{~L} / \mathrm{min}$, which Volpe et al ${ }^{10}$ suggested causes caudad secretion movement. These are the theoretical conditions, according to a series of laboratory based studies, for embedding mucus in the lungs. None of the patients received mechanical ventilation compatible with cephalad mucus movement or secretion clearance (expiratory flow bias of $10 \%$ or $17 \mathrm{~L} / \mathrm{min}$ ).

Volpe et al suggested that, while both were important, the inspiratory-expiratory flow difference was a better predictor of mucus displacement than PIF/PEF. ${ }^{10}$ However, the $17 \mathrm{~L} / \mathrm{min}$ threshold should be interpreted with caution. It is not a universal threshold, but pertains to the specific conditions in the experiments by Volpe et al (horizontal, rigid airway with inner diameter $1.0 \mathrm{~cm}$ and length $30 \mathrm{~cm}$, volume control ventilation, square-wave inspiratory flow, and simulated mucus). Our patients had the head of the bed elevated to $30-45^{\circ}$, which may have augmented gravity-induced caudad mucus movement. Furthermore, mucus thicker than the simulated mucus used by Volpe et al would presumably require a flow of more than $17 \mathrm{~L} / \mathrm{min}$ to move the mucus in either direction. Conversely, the $10 \%$ threshold proposed by Benjamin et $\mathrm{al}^{7}$ and $\mathrm{Kim}$ et $\mathrm{al}^{8}$ pertains to a broader range of simulated experimental conditions and may thus be more generalizable to clinical practice.

Sputum movement depends on mucus viscosity, mucus load, and the diameter of the airway. ${ }^{11,13}$ The smaller the airway diameter, the thinner the mucus layer required for mucus movement at a given gas flow. Mucus depth has to 


\section{Do Commonly Used Ventilator Settings Hinder Secretion Clearance?}

occupy at least $10 \%$ of the airway diameter in the large airways in order for 2-phase gas/liquid flow to occur. ${ }^{7,11}$ In the majority of patients, especially those with normal mucus production or good cough, the effect of ventilator flow bias may be clinically unimportant or negligible. However, in patients with mucus hypersecretion and inadequate airway defense mechanisms, prolonged ventilation with an inspiratory flow bias may embed mucus and cause serious respiratory complications.

It is unclear from the literature to what extent clinicians appreciate the effect that ventilator settings may have on inspiratory or expiratory flow bias. Clinicians are likely to set the ventilation mode, respiratory rate, tidal volume, airway pressures, and $\mathrm{F}_{\mathrm{IO}_{2}}$ on the prioritized basis of gas exchange, ventilation, and metabolic status. They may not give sufficient consideration to the effect of flow bias on mucus movement.

Chest physiotherapy including lung hyperinflation, positioning, and airway suctioning, can assist with short-term improvements in secretion clearance and lung/thorax compliance, ${ }^{14}$ but this may happen only sporadically during the day and even less frequently overnight. However, ventilator settings that cause an inspiratory flow bias throughout the remainder of the day and night, and counteract the benefits of secretion clearance maneuvers, may not optimize patient outcome.

The volume of gas moved in either direction is equal during normal respiration, but the peak or mean flow of the inspiratory and expiratory phases can differ substantially, and partly depends on the relationship between $T_{I}$ and $T_{E}$. In this study the relatively short $T_{I}$, in relation to $\mathrm{T}_{\mathrm{E}}$, reflected conventional ventilator settings. In the study by Volpe et al the influence of $\mathrm{T}_{\mathrm{I}}$ on mucus movement was significant in univariate analysis, but fell away in favor of PIF during multivariate analysis. ${ }^{10}$ Manipulating ventilator $\mathrm{T}_{\mathrm{I}}$ and $\mathrm{T}_{\mathrm{E}}$ to direct mucus movement is not common clinical practice, but may be a reasonable strategy for patients with mucus hypersecretion and poor secretion clearance.

Volpe et al demonstrated the benefits of inverse-ratio ventilation for enhancing secretion clearance in a bench model. ${ }^{10}$ However, inverse-ratio ventilation may have adverse effects on hemodynamic function and cardiac output, and is sometimes reported as uncomfortable by patients, ${ }^{15}$ so it may be challenging to achieve ventilation modes that promote mucus clearance. However, it should be relatively straightforward to achieve "neutral" mucus migration (flow bias of $<10 \%$ ) by avoiding ventilation settings that promote mucus embedding, such as some of those we observed in the present study. Reducing inspiratory flow bias in CPAP and pressure support modes may be feasible by adjusting the inspiratory ramp or rise time during pressure-supported breaths, but this requires investigation.
Enhancing airway secretion clearance may not always be desirable. For example, during the early stages of ARDS or pneumonia there may be noxious biofluids in the peripheral airways, and containing that inflammatory material through patient positioning and/or ventilation strategies may be a means to minimize the progression of infection. ${ }^{16,17}$

Current ventilator management strategies aim to minimize lung injury and infection through the use of low tidal volume (4-6 mL/kg), moderate to high PEEP, and headof-the-bed elevation up to $45^{\circ} .{ }^{18}$ However, controversially, recent research with a sheep model found that with headof-the-bed elevation, gravity hindered secretion clearance and increased the risk of lower-respiratory-tract infection. ${ }^{19}$ Hence, with the current standard head-of-the-bed elevation for pneumonia prevention, ${ }^{18}$ a ventilation strategy that generates an expiratory flow bias may play an even more important role to ameliorate the effects, but requires further investigation.

\section{Limitations}

We had a small sample size and a short observation period (50 ventilator breaths). In addition, we did not collect information on the presence of airway secretions during the observation period. However, there is currently no accepted standard for the diagnosis of secretion retention in the intubated and ventilated patient. We also did not assess changes in PIF/PEF bias with changes in ventilation mode or settings.

\section{Conclusions}

Future research should explore the effects of expiratory and inspiratory flow bias on secretion clearance/retention in intubated ventilated patients. Secretion removal may be an important goal when adjusting the ventilator. Sometimes a patient's competing clinical needs may preclude ventilator settings that promote secretion clearance, but if this potential hazard is borne in mind, then efforts to reduce the absolute PIF/PEF difference or flow bias may reduce the risks of ventilation, augment chest physiotherapy, and potentially reduce the need for invasive airway care such as bronchoscopy.

\section{REFERENCES}

1. Konrad F, Schreiber T, Brecht-Kraus D, Georgieff M. Mucociliary transport in ICU patients. Chest 1994;105(1):237-241.

2. McCool FD. Global physiology and pathophysiology of cough: ACCP evidence-based clinical practice guidelines. Chest 2006;129(Suppl 1):48S-53S.

3. Bauer T, Ferrer R, Angrill J, Schultze-Werninghaus G, \& Torres A. 2000, Ventilator-associated pneumonia: incidence, risk factors, and microbiology Semin Respir Infect 2000;15(4):272-279. 


\section{Do Commonly Used Ventilator Settings Hinder Secretion Clearance?}

4. Levine SA, Niederman MS. The impact of tracheal intubation on host defences and risks for nosocomial pneumonia. Clin Chest Med 1991;12(3):523-543.

5. Gal T. Effects of endotracheal intubation on normal cough performance Anesthesiology 1980;52(4):324-329.

6. Sackner MA, Hirsch J, Epstein S. Effect of cuffed endotracheal tubes on tracheal mucous velocity. Chest 1975;68(8):774-777.

7. Benjamin R, Chapman G, Kim C, Sackner M. Removal of bronchial secretions by two-phase gas-liquid transport. Chest 1989;95(3):658663.

8. Kim C, Iglesias A, Sackner M. Mucus clearance by two-phase gasliquid flow mechanism: asymmetric periodic flow model. J Appl Physiol 1987;62(3):959-971.

9. Freitag L, Long W, Kim C, Wanner A. Removal of excessive bronchial secretions by asymmetric high-frequency oscillations. J Appl Physiol 1989;67(2):614-619.

10. Volpe M, Adams A, Amato M, Marini J. Ventilation patterns influence airway secretion movement. Respir Care 2008;53(10):12871294.

11. Kim CS, Rodriguez CR, Eldridge MA, Sackner MA. Criteria for mucus transport in the airways by two-phase gas-liquid flow mechanism. J Appl Physiol 1986;60(3):901-907.

12. Main E, Castle R, Stocks J, James I, Hatch D. The influence of endotracheal tube leak on the assessment of respiratory function in ventilated children. Intensive Care Med 2001;27(11):1788-1797.
13. Jones A. Secretion movement during manual lung inflation and mechanical ventilation. Respir Physiol Neurobiol 2002;132(3):321-327.

14. Hodgson C, Denehy L, Ntoumenopoulos G, Santamaria J, Carroll $\mathrm{S}$. An investigation of the early effects of manual lung hyperinflation in critically ill patients. Anaesth Intensive Care 2000; 28(3):255-261.

15. Mercat A, Titiriga M, Anguel N, Richard C, Teboul JL. Inverse ratio ventilation $(\mathrm{I} / \mathrm{E}=2 / 1)$ in acute respiratory distress syndrome: a six-hour controlled study. Am J Respir Crit Care Med 1997;155(5): 1637-1642.

16. Graf J, Marini J. Do airway secretions play an underappreciated role in acute respiratory distress syndrome? Curr Opin Crit Care 2008; 14(1):44-49.

17. Graf J, Mentzelopoulos S, Adams A, Zhang J, Tashijan J, Marini J. Semi-quantitative tracking of intra-airway fluids by computed tomography. Clin Physiol Funct Imaging 2009;29(6):406-413.

18. Deja M, Hommel M, Weber-Carstens S, Moss M, Von Dossow V. Evidence-based therapy of severe acute respiratory distress syndrome: an algorithm-guided approach. J Int Med Res 2008;36(2): 211-221.

19. Bassi G, Zanella A, Cressoni M, Stylianou M, Kolobow T. Following tracheal intubation, mucus flow is reversed in the semi-recumbent position: possible role in the pathogenesis of ventilator-associated pneumonia. Crit Care Med 2008;36(2):518-525.

This article is approved for Continuing Respiratory Care Education credit. For information and to obtain your CRCE

(free to AARC members) visit 